\title{
Reflexões sobre o cenário artístico brasileiro dos anos 1940 aos anos 80: Entrevista com Catherine Bompuis, 2010
}

MARJOLAINE BEUZARD

Tradução de NIKOLETA KERINSKA

Marjolaine Beuzard é doutora em História da Arte Moderna e Contemporânea na Universidade Paris-Sorbonne. Em 2016, defendeu tese de doutorado sob a direção do professor Arnauld Pierre, intitulada "Abraham Palatnik, pionnier brésilien de l'art cinétique". Seus interesses de pesquisa incluem arte européia e não-européia, a relação entre arte e ciência, arquitetura, abstração geométrica e práticas multi-médias experimentais da arte cinética à arte cibernética.

AFILIAÇÃO: Université Paris Sorbonne, Histoire de l'art, Paris IV, Paris, France.

Nikoleta Kerinska é doutora em Artes Plásticas, Estética e Ciência da Arte pela Universidade de Paris I, Panthéon-Sorbonne (2014). Pesquisadora do grupo Fictions \& Interactions da Universidade de Paris 1 Panthéon-Sorbonne sob a coordenação de Bernard Guelton. Professora de arte computacional na Universidade Federal de Uberlândia. Sua pesquisa artística inspira-se pelas convergências/divergências nos processos de comunicação homemmáquina, que fazem uso da linguagem natural, como também pelas relações poéticas entre linguagem natural e imagem.

AFILIAÇÃO: Universidade Federal de Uberlândia, Uberlândia MG, Brasil 
- RESUMO

Nesta entrevista com Marjolaine Beuzard, a curadora de arte de origem francesa Catherine Bompuis propõe uma leitura do contexto da arte brasileira entre 1940 e 1980. Ela relata o modernismo brasileiro, aponta as especificidades da arte brasileira dos meados do século 20, e analisa as ideias de Mario Pedrosa sobre a arte, a sociedade e a política. A originalidade dessa entrevista entremeia-se com o prazer de saborear as trajetórias da arte contemporânea brasileira na perspectiva de um olhar externo e abrangente, que tece relações entre as cenas artísticas européia e latino-americana.

\section{PALAVRAS-CHAVE}

Neoconcretismo brasileiro, Mario Pedrosa, arte contemporânea brasileira

\section{ABSTRACT}

In this interview with Marjolaine Beuzard, the independent french curator Catherine Bompuis analyses the context of Brazilian art between 1940 and 1980. She talks about Brazilian modernism, points out the specificity of Brazilian art from the mid20th century, and expose Mario Pedrosa's ideas about art, society and politics. The originality of this interview is interspersed with the pleasure of savoring the trajectories of contemporary Brazilian art in the perspective of an external and comprehensive look that links European and Latin American artistic scenes.

\section{- KEYWORDS}

Brazilian neo-concretism, Mario Pedrosa, Brazilian contemporary art 
A entrevista feita por Marjolaine Beuzard com Catherine Bompuis foi realizada em março de 2010 como parte da pesquisa de sua tese de doutorado Abraham Palatnik, pioneiro brasileiro da arte cinética (1948-1984) defendida na Universidade de Paris Sorbonne em 2016.

Curadora independente de origem francesa e ex-curadora do Museu Nacional de Arte Moderna - Centre Pompidou, Paris, Catherine Bompuis vive e trabalha no Rio de Janeiro. Ela colaborou na publicação da antologia Mário Pedrosa: Documentos Primários (2016) com os editores brasileiros Paulo Herkenhoff e Glória Ferreira. Essa publicação foi coordenada pelo diretor do programa internacional do MoMA, o americano Jay Levenson (o projeto editorial foi iniciado na ocasião da exposição de Lygia Clark no MoMA de Nova York em 2013).

Marjolaine Beuzard: Qual foi a relação entre Mario Pedrosa e Merleau-Ponty? 0 que approxima ou diverge as ideias de Pedrosa e as do filósofo? Qual foi a recepção do livro A Fenomenologia da Percepção, de Maurice Merleau-Ponty (1945), no Brasil entre o final da década de 1940 e a chegada do Neoconcretismo em 1959? Como situar as contribuições de Merleau-Ponty em relação a Pedrosa? 0 crítico escreveu textos teóricos desenvolvendo essa questão? Como ele desenvolveu seu pensamento crítico?

Catherine Bompuis : É verdade que, este é um dos livros que Pedrosa cita com frequência, e uma de suas de referências de base, junto com A filosofia das Formas Simbólicas de Cassirer. Ele se interessa pelo trabalho de Focillon, mas também por Macluhan e pela teoria da mídia e da informação. Tudo isso faz parte de seus livros de referência. Um trabalho mais aprofundado deve ser feito sobre A fenomenologia da percepção e sua importância. Há sempre alguns livros que nos influenciam em certos momentos. Do meu ponto de vista, Mario Pedrosa foi um humanista, ele foi marxista, fazia parte do Partido Comunista, foi secretário da Quarta Internacional sob o nome de Blum, mais tarde excluído por Trotsky, depois socialista, prefigurando o movimento dos trabalhadores de Lula, ele sempre teve uma conexão extremamente forte com a política. Mas antes de tudo, eu o considero como humanista na medida em que ele estava muito interessado no que acontecia no interior do sujeito, para ele, a arte era um pensamento não verbal. Alias, Lygia Clark trabalhou muito a questão do pensamento não-verbal em toda sua prática sobre a terapia dos objetos relacionais. Como ela passa o objeto no corpo da pessoa para provocar nela sensações primárias. Lygia Clark também foi muito influenciada por essa questão, a questão da percepção, o que está acontecendo no corpo, que relação com a pessoa, com a arte, que emoções ela pode sentir, que são não verbalizadas durante sua relação com o objeto. E é verdade também, que a partir daí, a arte brasileira investiga a relação sujeito/objeto... Como dizia Mario Pedrosa, não de forma contemplativa, mas de tal forma que, finalmente, o espectador faz sua própria criação com o objeto, ou seja, ele precisa do objeto para poder criar algo ele mesmo. Em 1959 Lygia Clark fez Os Bichos, que são objetos feitos para serem manipulados. A cada manipulação feita, o espectador é forçado para uma relação diferente, há uma relação física que começa a se estabelecer, e tudo isso evoca, mesmo que indiretamente, uma questão muito importante, esta da fenomenológia da percepção. Dito 
isto, não devemos esquecer que o Brasil é um sincretismo total, Mário Pedrosa dizia que o Brasil é um anacronismo e uma promessa, portanto, uma mistura. Como eu disse, ele também definia a arte brasileira como uma síntese entre influências vindas de fora e o próprio à alma brasileira; acima de tudo é essa mistura, as influências estão lá, são misturadas, são digeridas, são canibalizadas, são "antropofagizadas", para serem transformadas em outra coisa.

A questão não é aplicar regras, mas transformar essas regras para alcançar outra coisa, e essa outra coisa, torna-se realmente importante com o neoconcretismo, ou seja, naquele momento em que invertemos a relação sujeito / objeto, é o sujeito que cria. O sujeito cria o objeto, e o objeto não se encontra mais num estado contemplativo - que Mario Pedrosa chamou de sua "solene solenidade"-, mas se trata de uma relação física, que é estabelecida com o objeto e que inverte o relacionamento. Isso é extremamente importante, e será continuado de maneira extraordinária por artistas como Lygia Clark ou Hélio Oiticica, que vão da abstração aos Parangolés, essas espécies incríveis de cores, que Hélio veste para acompanhar o povo da Mangueira. Na arte brasileira, há essa trajetória particularmente interessante, como finalmente se passa de uma influência extremamente forte nos anos 50 a 56, das influências externas do concretismo, muito presente não só na América Latina, mas também na Europa, ao neoconcretismo, que é um ramo dissidente, e que ao mesmo tempo inverte a relação entre sujeito e objeto. A verdadeira força da arte brasileira, que nasce naquele momento, e que pertence realmente a esta arte, de maneira decisiva é o neoconcretismo, e, não o concretismo... Tudo aquilo que pertence ao ser humano e ao seu sistema de percepção fascina profundamente Mario Pedrosa, e, claro, e A fenomenologia da percepção é, sem dúvida, um dos seus cinco ou seis livros de cabeceira.

\section{MB : Como Mário Pedrosa conheceu a Dra. Nise da Silveira? Em que contexto? Você a conheceu?}

CB : Nise da Silveira era comunista e uma das primeiras médicas. Ela foi transferida na década de 1940 para o hospital psiquiátrico Dom Pedro II, fora da cidade do Rio de Janeiro, onde permaneceu toda a sua vida, e também foi presa lá. Como eles se conheceram, eu não sei. O que eu sei é que em 1946, ela começou a criar tendo como referência as idéias junguianas, pois ela era junguiana. Alias, ela conheceu Jung em um congresso de psiquiatria em 1959. Ao criar seus ateliês de terapia ocupacional em 1946, ela começou a usar esse método porque era contra os eletrochoques, que eram usados na época para o tratamento de esquizofrênicos. Ela achava que o eletrochoque não fazia sentido. Ela os usou uma vez em um esquizofrênico e jurou que nunca mais faria isso. Ela era uma mulher forte quando a conheci. Ela mesma conta que estava neste hospital com esquizofrênicos, onde não havia nada, quando pegou uma meia, e começou enrolá-la, fazendo os outros brincar com ela. $\mathrm{O}$ esquizofrênico é cortado de todo o afeto, à medida que sua doença se desenvolve, ele tem menos e menos afetos, que são colocados em prática. Para isso, ela pediu alguns artistas para trabalharem com eles; mais tarde introduzindo também contato com animais. Ela sempre viveu com dezenas de gatos em casa. $O$ Museu dos Estados do Inconsciente ainda está cheio de gatos, pois os pacientes 
conseguem ter uma relação afetiva com a pintura, assim como com os animais. Ela acredita que é essencial para a recuperação do esquizofrênico. Ela também era grande admiradora de Antonin Artaud, fez um pequeno livro e uma pequena exposição intitulada "Os inúmeros estados de ser", onde Artaud dizia que o ser passa por estados cada vez mais perigoso para si mesmo. Ela adorava também Spinoza. Ela era uma mulher de espírito forte, e alguns de seus pacientes desenvolviam trabalhos realmente incríveis, eles eram artistas surpreendentes, que produziam obras magníficas. É verdade que ela sempre se recusou a considerar essas obras como arte, mas como terapia médica, que ajudava no tratamento da doença. Numa certa época, quando Mario Pedrosa retornou ao Brasil, ele foi exilado muitas vezes, ele não tinha nada. Ele vivia de maneira muito modesta, e ela ofereceu-lhe um pequeno emprego. Eles provavelmente eram comunistas, suas relações nem sempre eram fáceis, e seus pontos de vista divergiam, porque, para Pedrosa, o que os pacientes faziam era arte, mas não para ela. Ainda, trabalhando no Museu de Imagens do Inconsciente, Mario se tornou proximo aos trabalhos dos doentes mentais, e começou a fazer uma seleção de obras, a escrever sobre elas como crítico de arte. Ele escreveu como crítico de arte sobre os trabalhos dos doentes mentais, bem como sobre os trabalhos das crianças, não havia segregação, ele era alguém muito aberto, nem um pouco fechado em um pensamento sectarista. Ele escreveu textos muito bonitos sobre um dos doentes mentais, Raphael [Domingues] que, quando desenhava nunca tirava a ponta do lápis e seu desenhou sempre foi feito em um único gesto. Em 1927, ele conheceu os surrealistas (o cunhado de Benjamin Perret), e foi amigo de Tanguy e Breton. Muito mais tarde, ele mostrará os desenhos de Raphael para Breton, com quem permaneceu em contato, e Breton os achou mais bonitos do que os de Matisse. A partir daí, foi criado o Museu de Imagens do Inconsciente, houve vários catálogos e ele começou a fazer um trabalho quase de curador com as obras dos doentes mentais, tentando concerva-los embora as condições sempre precárias. Assim, ele começou a elaborar a concepção do museu, porque, finalmente, o que é um museu? Isto deve ser uma casa, onde as pessoas vêm para passar um tempo, fazem o que querem fazer, e espaço deve estar aberto. Finalmente, dentro do hospital psiquiátrico, havia um pequeno prédio chamado "Museu de Imagens do Inconsciente", onde os pacientes podem entrar e sair e eu tive sorte, quase vinte anos atrás, de ver uma exposição de [Fernando] Diniz que viveu toda sua vida em um hospital psiquiátrico e que agora falesceu. Eu o conheci e almocei com ele. Foi uma retrospectiva magnifica de Diniz no Paço Imperial em 1991. Foi de uma sensibilidade incrivel, toda essa questão da sensibilidade de que falamos, e que foi fundamental para Mario Pedrosa. Ele dizia que a sensibilidade é a inteligência para o artista, que a inteligência para o artista é o sensível. Nós estávamos em uma área, que era sensível, caso contrário, nada existe. E nesta retrospectiva, no Paço Imperial (RJ), Diniz estava sentado no chão e ainda pintava porque não queria largar o trabalho. Assim foi criado o Museu de Imagens do Inconsciente em 1952. Ele abriu toda esta relação, ele estava tão interessado em Merleau-Ponty, como em Freud e Jung. Através de Jung, toda a questão do inconsciente coletivo é colocada. Há sucessões de mandalas feitas pelos doentes. Existe um filme muito bom sobre o trabalho de Nise da Silveira, que dura várias horas, onde vemos os pacientes que estão pintando em cavaletes num parque. O que é 
muito bonito no filme é que artistas como Serpa e Mavignier estão de pé atrás dos pacientes que estão sentados. Num momento, há uma mulher esquizofrênica que foi assassinada mais tarde por um paranóico, ela vira para o artista e o olha, sentese uma cumplicidade no nível do olhar, isto não é verbalizado, mas há algo acontecendo, e isso que acontece faz com que ela possa pintar, ou seja, isto indica uma maneira de reintroduzir a afetividade para alguém que está perdendo suas emoções, e toda esta questão. Finalmente, estes artistas fazem trabalhos incríveis, e Pedrosa vai escrever sobre eles como crítico de arte, como escreveu sobre Matisse, e isso é muito bom, é uma grande lição.

MB : Essa dimensão afetiva convida a nós debruçarmos sobre uma questão que diz respeito à tese de Mario Pedrosa "A natureza afetiva da forma na obra de arte" ...

CB : Esta dimensão afetiva é predominante em todos seus escritos. Para mim, o que mais me interessa em Mario Pedrosa, ainda a primeira vez que o li, é essa dimensão afetiva. Finalmente, ele me interessa como ser humano, e, como ser humano sensível. E essa dimensão afetiva, quando ele escreve, é flagrante. Ele escreve com afeto, carinhosamente, com paixão, e ele trabalha com essa questão, dizendo que é fundamental para a arte. Mario introduz todas a problématica da sensibilidade. Ele fala muito bem de Hölderlin, por exemplo, que, no auge de sua loucura, era incompreensível oralmente para seus próximos, mas quando escrevia, era de uma clareza admiravel. Essa dimensão afetiva que o artista tem com a forma, e que o espectador tem também, é a partir daí que se constrói tudo.

MB : Isto é pensado na perspectiva do relacionamento ... você pode me falar mais sobre essa problemática?

CB : É uma questão de sensibilidade, ele escreveu vários textos sobre a questão da sensibilidade. Na verdade, ele trabalhou com Nise da Silveira, na época, eles inauguram o Museu de Imagens do Inconsciente em 1952. Quando em 1976, o Museu de Arte Moderna do Rio de Janeiro queima, ele propõe uma reformulação de um museu que abarcaria não somente arte moderna e arte contemporânea, mas também arte de doentes mentais, arte de índios, e, que poderia absorver todas essas categorias periféricas que são rejeitadas pela sociedade. É um ponto de vista político e bastante revolucionário para a época. Isso não vai acontecer. É o que ele chamou de reformulação do museu de arte moderna, - uma proposta aberta que acolhe sem discriminação o que não é considerado arte, socialmente e institucionalmente.

MB : Quais foram as relações entre Mario e Léon Degand [1907-1958]? Ele o conheceu na Europa antes de sua exposição Da figuração à abstração para a inauguração do Museu de Arte Moderna de São Paulo em 1949?

CB : Não há praticamente textos nos quais ele fala de Leon Degand, mas ele organizou uma visita com Léon Degand e Meyer Schapiro [1904-1966] ao hospital psiquiátrico. Schapiro disse que, o que mais o impressionou no Brasil foi esta visita ao 
Museu de Imagens do Inconsciente. Mesmo Jung, em 1959, ficou muito surpreso com o trabalho dos doentes mentais, dizendo que as pessoas que trabalham com eles não têm medo do inconsciente, mantendo relações extremamente próximas e afetivas com os doentes, de modo que os trabalhos dos doentes foram diferentes, sem estarem restritos num sistema... Léon Degand teve contatos com Pedrosa, foi defensor da abstração como Mario Pedrosa, e houve terríveis combates no Brasil com uma parte muito reacionária e acadêmica. Foi uma luta que não foi vencida antecipadamente, também como na França.

MB : Houve o mesmo tipo de problemas e controvérsias na Europa em torno do debate a favor ou contra a abstração. Parece que no Rio de Janeiro, isto aconteceu de maneira diferente, emergiu uma oposição entre abstração geométrica e fria, de um lado, e abstração lírica e quente, de outro. Você poderia falar mais sobre isso ...

CB : É muito interessante essa abstração quente, e, essa abstração fria. É a mistura total com o concretismo, ou seja, o concretismo poderia ser ou a abstração fria ou a abstração quente, sem ser a abstração lírica, esta ideia é alimentada pelas teorias da Gestalt e da forma afetiva da obra de arte, colocando em echeque a classificação européia, se situando entre as duas. Isto que pode ser qualificado como abstração fria é, na verdade, uma abstração quente, pois é focada em afetos.

MB : O que pode parecer ambíguo é o fato que, o próprio Palatnik descreve seu trabalho como expressão concreta ...

CB : No início, foi chocante porque estamos condicionados por uma certa história da arte pós Segunda Guerra Mundial, escrita pelos americanos e pelos europeus, que começava a declinar. É uma maneira diferente de abordar as coisas e de neutralizar as classificações estabelecidas pela história da arte na Europa e nos EUA. Ao mesmo tempo, Pedrosa escreveu alguns textos muito virulentos contra a abstração lírica, que era semelhante à caligrafia japonesa, mas sem ser uma caligrafia de fato, Mario tinha estudado a caligrafia e o seu significado no Japão, e as pinturas de [Georges] Mathieu não passavam de imitações, alias, na época Mathieu veio para o Rio; essa teatralidade do gesto para Mario era imperdoável. Se integrar ao objeto, expressar sua individualidade, Pedrosa achava isso lamentável. Ele escreveu textos acrimoniosos sobre Mathieu, onde o massacrou. Pollock também não escapou, ele o comparava a James Dean. Mas toda essa arte informal, lírica não interessava absolutamente pare ele.

MB : Pedrosa escreveu para o grupo de artistas abstratos que eles formaram juntos no final da década de 1940 no Rio de Janeiro? Você poderia me contar sobre Palatnik e sua relação com Ivan Serpa e Almir Mavignier?

CB : Palatnik estava especialmente interessado em pintar e quando viu as obras dos doentes mentais, ele parou porque havia uma tal riqueza de linguagem nas pinturas dos esquizofrênicos, com uma imaginação completamente transbordante; eles não 
se impunham limites, tão livres em sua criação, e principalmente, o trabalho com a línguagem sempre foi incrível. Foi a partir daí que ele decidiu redirecionar completamente seu trabalho.

\section{MB : No contexto do grupo Frente em 1954, quais eram seus relacionamentos? Você pode esclarecer a posição de Pedrosa e sua contribuição para a arte bra- sileira, sabendo que já na década de 1960 ele introduziu a ideia do pós-moder- nismo?}

CB : Mario Pedrosa federou tudo. Não podemos entender a arte brasileira se não conhecermos Mario Pedrosa. Ao mesmo tempo, sua personalidade explode, ele teve contatos com Romero Brest, politicamente engajado na Argentina. Ele introduziu o marxismo no Brasil. Ele era um crítico de arte, mas também um político, ele era um ativista. Não podemos fazer as coisas "à la francesa", não podemos frangmetar, senão não entenderemos nada, nos perderemos completamente, as coisas são as mais contraditórias possíveis. O Brasil é uma contradição total. É um anacronismo e uma promessa, como diz Mario Pedrosa, é um paradoxo total. Sim, ele foi muito importante para a abstração, pode-se dizer até mesmo para o modernismo, com todo esse projeto utópico que está por trás do modernismo. O que é modernismo? É um desejo de mudar a sociedade, é um desejo de construir. O que os primeiros modernistas, os construtivistas queriam se não for mudar a sociedade, mudar o mundo. $O$ que Vladimir Mayakovsky e El Lissitzky queriam fazer? É muito interessante ver os Prouns de El Lissitzky, e as instalações de Helio Oiticica e de Lygia Clark. Existe, portanto, esse projeto moderno, que é um projeto utópico, mas também um projeto social, e está relacionado à trajetória política de Mario Pedrosa. Ele introduziu, ele abriu o Brasil para a modernidade desbravando um meio extremamente fechado, acadêmico, de maneira virulenta, polêmica. Ele era um apóstolo da abstração. Por que ele gostava tanto de arte moderna? Por que ele a defendeu tanto? Porque a arte moderna tinha vindo de todas as fontes primitivas, era uma linguagem universal, era uma linguagem que todos podiam entender, sem falar a mesma língua.

A linguagem das formas é uma linguagem qui se dirige a cada pessoa, sem discriminação. A lingua é uma barreira, a arte moderna fala a todos. Houve este universalismo da arte moderna que foi muito importante, cujo declínio muito rapidamente percebido. Sem duvida, Mario é um dos primeiros críticos de arte a sentir esse declínio muito rapidamente. Ele começa a se envolver em outras direções. Por ser um homem político inteligente, prudente e ativista, ele previu o pós-modernismo no final do modernismo. Ele amava artistas como Klee, que estavam tentando ter esta abertura universal através da linguagem das formas, e finalmente com a sociedade, tal como ela é implementa - uma sociedade de consumo, - onde a arte se torna um elementos de propaganda, de política e de publicidade. Eu acho que sua análise do pós-modernismo é uma análise política. É interessante identificar nas suas escritas o uso de adjetivos para alguns artistas que ele admira: ele fala de arte revolucionária em relação aos trabalhos de Lygia Clark e de anarquismo para os trabalhos de Hélio Oiticica. Este é o maior elogio que ele poderia dar para eles. Isto pertence ao vocabulário político. Não podemos separar a dimensão crítica da arte de sua dimensão política, e as relações são entrelaçadas, pois para ele, a arte é 
uma questão política; a arte deveria integrar, ou seja, a arte é um fator de integração, que deveria ser capaz de mudar as coisas, de movimentar a sociedade.

Mario Pedrosa é um intelectual global. Ele é um dos primeiros intelectuais globais, antes de todos os outros, porque sua trajetória é política, ele foi exilado várias vezes, primeiro ele foi estudar filosofia em Berlim, em seguida ele é exilado nos EUA, depois na França, por isso, ele tem uma visão extremamente informada. $\mathrm{Na}$ época da ditadura, pouquíssimas coisas do que acontecia fora chegava aqui, houve uma censura enorme. Durante o período de ditadura de 1964 a 1984, não havia nada, nem jornais, e, os artistas estavam em total ausência de informação, do que estava acontecendo no mundo; existia então uma demanda enorme, e ele no seu exílio, esteve em contato com muitos outros movimentos artísticos ao redor do mundo, tornou-se amigo de muitos artistas, incluindo Calder, com quem teve uma longa amizade. Quando retornou ao Brasil, após esses exílios suscetivos, ele escreve em vários jornais, inclusive no Jornal do Brasil, no Correio da Manhã. Essa experiência the permitiu de falar sobre tudo, sobre Rauschenberg, sobre Calder e Pollock, sobre a Escola de Paris, e os surrealistas, porque ele teve contatos importantes e a oportunidade de circular. Ele foi expulso do Brasil, e isso lhe permitiu de transformar as tragédias de uma vida inteira em vitória, e dela fazer uma arma. É uma abertura extraordinária num país enclausurado pela ditadura. É uma respiração, um sopro de ar fresco para a situação artística brasileira. A questão do canibalismo é todo o manifesto da antropofagia, que faz parte da cultura brasileira, "só a antropofagia nos une contra o mundo reversível e as ideias objetivadas". É o canibal que se apropria do mal do colonizador. É o que traz a cultura brasileira, e, isto é muito importante.

MB : Palatnik diz que Mario Pedrosa lhe emprestou um livro sobre a cibernética? Pedrosa escreveu especificamente sobre a cibernética e a sua relação com a arte? Essas ideias são desenvolvidas em seus estudos em relação a teoria da Gestalt?

CB : Mario Pedrosa adorava a arte e a ciência. Ele pensava que a ciência chegou num ponto em que não podia mais representar uma imagem do mundo. Ele escreveu vários textos sobre arte e ciência. Ele abriu tudo, ao contrário de Clement Greenberg, que se trancou num formalismo aterrorizante. Ele foi anti-Greenberg por excelência, isto é, ele integra tudo: arte e inconsciente, arte e política, arte e ciência, arte e arquitetura. Ele analisa tudo isso, propondo aberturas. $\mathrm{O}$ grande interesse de seu pensamento é, que ele é curioso e aberto, que empata toda tentativa de classificação, todo enclausamento. A história da arte para ele é interessante somente se ela for confrontada a outros campos do saber, a outros domínios do pensamento, então ele a confronta para despedaçá-la. Este é um pensamento extremamente subversivo para a época. Num certo momento, há quase um retorno à ordem no campo da história da arte, ou ainda como nos EUA, onde durante a Guerra Fria, o expressionismo abstrato se tornou para o governo americano, um instrumento que serviu para demostrar a liberdade do artista.

\section{MB : Qual foi a relação entre Pedrosa e Palatnik até o falecimento do crítico em 1981?}


CB : Pedrosa defendeu Palatnik em todos os seus textos. Palatnik tem grande admiração por Pedrosa, ele o introduziu ao marxismo, a Freud e Jung, e também a uma ampla variedade de leituras que ele não tinha. Pedrosa era um ponto de encontros e descobertas, a porta dele estava sempre aberta. Ele adorava conversar, amava as pessoas, amava os artistas, que podiam vir a qualquer hora do dia ou da noite para conversar com ele; sua casa estava sempre cheia. Ele amava o contato humano, ele era emotivo, afetivo. Assim que um artista fazia algo, ele entrava em contato logo. Imagino que, com Palatnik, ele tivesse a mesma relação. Mesmo mais tarde, quando Antonio Manuel se despiu no Salão de Arte Moderna em plena ditadura, Mario o chamou para falar sobre isso. Em seguida, fez um texto sobre ele. Com Lygia Pape teve uma ligação muito próxima. Eles eram amigos, antes de tudo, eram as relações humanas. O mais importante para ele era a pessoa, e, o que existia como mais humano, como expressão propriamente humana, era a arte.

\section{MB : Como você vê o trabalho de Palatnik? Suas liga ções com a arte cinética, o movimento neoconcreto e a arte tecnológica ?}

CB : É difícil esboçar um panorama da arte brasileira, porque todos os artistas são muito diferentes. Fisicamente, os brasileiros são tão loiros de olhos azuis, quanto morenos de olhos verdes. É um pouco parecido com os artistas. Palatnik trabalhou no seu canto, ele não sabia nada sobre cinética. Ele fez sua pesquisa, e penso, que nem sequer foi considerado um artista cinético na lista de Frank Popper, como mais tarde, a partir de 1964. A história da arte é desinteressante quando é uma classificação fria, um inventário seco, isso não faz sentido. Mario Pedrosa também estava cansado de "ismos", foi a grande moda: novo realismo, cientismo, expressionismo, a era dos "ismos", ele achava isso completamente obsoleto, esse modo de considerar a arte como se nós fizemos um inventário. Felizmente, os "ismos" desapareceram nos anos sessenta. É verdade que existem características comuns entre artistas brasileiros, mas o mais interessante é ver as diferenças, ver o que os diferencia um de outro.

Nessa lógica, Palatnik foi cinético antes do tempo, mas também foi muito diferente de Soto, Agam, Schöffer ou Le Parc. É mais interessante distinguir as diferenças dentro dos movimentos. Há também o contexto que é importante para o artista e, sem duvida, Palatnik é pioneiro da arte cinética no Brasil, o que não era óbvio no início, mas foi reconhecido mais tarde. Frederico Morais trabalhou muito com Pedrosa, ele tem um grande respeito e uma grande amizade por Mario. Pedrosa não influenciou somente os artistas, mas também os críticos de arte. O concretismo sem Mario Pedrosa não existiria, e, provavelmente o neo-concretismo também não. Ele colocava as qualidades humanas acima de tudo. Palatnik é quase um pesquisador, um pouco como um cientista louco. Há alguns meses, eu vi uma exposição, onde ele mostrou alguns filmes curtos, muito legais e bem humorados. Havia pequenos dados magnéticos, com os quais ele brincava. Há sempre muitas influências, e isto é inconsciente. O Brasil é uma "terra de contrastes", é difícil identificar uma identidade brasileira, mas, se existir, ela é reivindicada no período do neoconcretismo. Os brasileiros estão sempre a procura de uma identidade. É um povo que foi colonizado, eles tentaram colonizar os índios, mas os índios preferiram cometer 
suicídio; em seguida, eles trouxeram escravos da África. Existem identidades que se misturam no Brasil. Pode-se dizer que a identidade brasileira é a mistura, é um sincretismo, o completamente oposto à ideia de pureza. O Brasil sempre teve uma fome canibalista por tudo que vem do exterior, e, o desejo contraditório e, às vezes contestado, de constituir no mesmo espaço, uma imagem que os representa como um todo. O Brasil reivindica o todo - nos somos o todo, - não somos isso ou aquilo, mas o todo, absorvemos tudo, fizemos o que queríamos, somos o todo. Essa é a identidade brasileira, é a reivindicação do todo, é uma síntese que toma tudo, canibalizando absolutamente o colonizador, a imagem do colonizador, e todas as influências estrangeiras que aí estão.

\section{Bibliografia Indicativa}

BOMPUIS, Catherine, «A Revolution of sensivisity », in : Eds. FERREIRA, Glória, HERKE-

NHOFF, Paulo, Mário Pedrosa Primary Documents. New York : The Museum of Modern Art, 2015, p. 52-57.

ESPADA, Heloisa, «Mário Pedrosa et l'abstraction géométrique au Brésil : pour un « constructivisme " non dogmatique ", Critique d'art [En ligne], 47 | Automne / Hiver 2016, mis en ligne le 30 novembre 2017, consulté le 25 février 2018. URL : http://journals.openedition.org/critiquedart/23253; DOI : 10.4000/critiquedart.23253

FERREIRA, Glória, "Neoconcretismo, la théorie et la pratique », in : Mémoires croisés, dérives archivistiques: Archive de la critique d'art, Paris : Institut national d'histoire de l'art, 2015, p. 46-49.

MERLEAU-PONTY, Maurice. La phénoménologie de la perception, Paris : Gallimard, 1945.

Recebido em 21/10/2018 - Aprovado em 21/11/2018

Como citar

BEUZARD , M. KERINSKA, N. (tradução) Reflexões sobre o cenário artístico brasileiro dos anos 1940 aos anos 80: Entrevista com Catherine Bompuis, 2010ouvirOUver; Uberlândia, v.14,n.2, p.594-604, jul./dez. 2018. Disponível em: http://www.seer.ufu.br/index.php/ouvirouver; DOI:http://doi.org/10.14393/OUV23-v14n2a2018-24

A revista ouvirOUver está licenciada com uma Licença

Creative Commons Atribuição-NãoComercial 4.0 Internacional. 